Kyoto University,

Graduate School of Economics

Discussion Paper Series

Identifying the Effect of Mobile Operating Systems on the Mobile Services Market

Toshifumi Kuroda Teppei Koguchi Takanori Ida

Discussion Paper No. E-17-004

Graduate School of Economics Kyoto University

Yoshida-Hommachi, Sakyo-ku

Kyoto City, 606-8501, Japan

July, 2017 


\title{
Identifying the Effect of Mobile Operating Systems on the Mobile Services Market*
}

\author{
Toshifumi Kuroda, Tokyo Keizai University ${ }^{\dagger}$ \\ Teppei Koguchi, Shizuoka University \\ Takanori Ida, Kyoto University
}

Keywords: Mobile phone, Handset, Internet service, Platform competition

JEL classification: L12, L43, L96

\begin{abstract}
Modern economic theory predicts that tying can serve as a tool for leveraging market power. In line with this economic theory, competition authorities regulate the tying of Microsoft Windows with its Media Player or Internet browser in the EU and Japan. The authorities also take note of the market power of mobile handset operating systems (OSs) over competition in the app and services markets. However, no empirical evidence has thus far been presented on the success of government intervention in the Microsoft case. To assess the effectiveness of government intervention on mobile handset OSs, we identify the extent to which complementarity and consumer preferences affect the correlation between mobile handset OSs and mobile service app markets (mail, search, and map). We find significant positive complementarity between the mail, search, and map services, and mobile handset OSs. However, the elasticities of the mobile handset OS-mobile service correlations are rather small. We conclude that taking action to restrict mobile handset OSs is less effective than acting on mobile services market directly.
\end{abstract}

\footnotetext{
* This analysis employed data from the Statistical Surveys for the Competition Review in the Telecommunications Business Field in Fiscal Year 2011 and 2014. We are grateful to the staff at the Japan Ministry of Internal Affairs and Communications (MIC) for assisting to access the data. We thank the participants of JSPU2012 and Competition and Public Policy in Network Industries at Kwansei Gakuin University for their helpful comments. We also thank Jiro Nemoto and Akio Torii for their helpful comments. We have read and understood IEP policy on declaration of interests. Takanori Ida was board member of MIC from 2006 to 2014 and Teppei Koguchi was employed by MIC from 2009 to 2011. Toshifumi Kuroda served as a consultant for NTT DoCoMo at 2005-6. This work was supported by JSPS KAKENHI Grant Number JP22730207.

$\dagger$ Corresponding author.

Tokyo Keizai University, 1-7-32, Minami-cho, Kokubunji-shi, Tokyo 185-8502, Japan (e-mail: kuroda@tku.ac.jp).
} 


\section{Introduction}

There has been stiff opposition to Microsoft's excessive control of the personal computer (PC) operating system (OS) market in the United States, Europe, and Japan. The US Federal Trade Commission brought a lawsuit against Microsoft, accusing the company of abusing its market power and threatening rival companies, thus harming consumers. To redress such anti-competitive conduct, the European Commission prohibited Microsoft from offering its Windows OS with Media Player included. Moreover, the Japan Fair Trade Commission admonished Microsoft for bundling its Office software with its Internet browser.

Recently, competition authorities have focused on the abuse of the control of the smartphone OS market by Google. In April 2016, the European Commission warned that Google was most likely abusing its dominant position compared with Android device manufacturers and mobile network operators in the search and smartphone OS markets. In October 2015, the Russian Federation Antimonopoly Service approved a lawsuit filed by the competitor search site Yandex against Google for violating the rules designed to protect competition and ordered Google to pay fines.

At issue is whether the OS market can be controlled by tie-ins of application software with smartphone OSs, which are then used to leverage application software. The Chicago School theory (Posner, 1976) holds that monopolies using tie-ins do not raise their profits. However, recent theoretical research has found that tie-ins can be used to leverage market control (Whinston, 1990; Carlton and Waldman, 2002) as well as prevent market entry (Nalebuff, 2004; Choi and Stefanadis, 2001).

Accordingly, the effect on the market of Microsoft tying its Media Player and Internet browser to its OS is unclear, as are the results likely to be achieved by the actions of the competition authorities. In particular, the extent to which OS tie-ins or interventions affect economic welfare is not known (Gilbert and Katz, 2001; Klein, 2001; Whinston, 2001). Moreover, although Microsoft's share of the PC OS market has remained high, whether its market power has extended to the smartphone OS and Internet service markets and the nature of its response to governmental interventions remain unclear.

To consider the effectiveness of governmental intervention in the smartphone market, the present study quantifies whether a complementary relationship exists between mobile phone OSs and services. For our analysis, we use data taken from a consumer survey that examined the choice of mobile phone OSs and services at two points in time (2012 and 2015) in Japan, which has seen a rapid spread in mobile Internet usage. Specifically, the mobile phone OS in our analysis comprises the three OSs of Japanese mobile phone carriers at that time (iMode, EZWeb, and Yahoo! Ketai) as well as Google Android, Apple iOS, and Microsoft OS (Windows Mobile) commonly used in today's market.

The users of a mobile phone OS produced by a certain company tend to use the services of that company more than do other handset users. However, it remains unclear whether this is because of product quality (e.g., the complementarity of the mobile phone OS and 
services) ${ }^{1}$ or a result of consumer preferences (e.g., brand preferences for certain carriers). To identify the correlation between the mobile handset OS and service owing to brand preference and the complementarity of services and handsets, the present study examines the market price for mobile handsets, which affects handset choice but not service choice, as instrumental variables. This approach enables us to divide the correlation between mobile handset OSs and services into complementarity with consumer preference correlations.

We find that the choice of a mobile phone OS significantly affects the choice of mail, search, and map services. Furthermore, while the OSs of Japanese mobile phone carriers were influential in guiding customers to the company's services in 2012, this influence weakened in 2015 with the rising presence of the OSs of Google and Apple. Between 2012 and 2015, the elasticity of the increase in users of Google Search produced by an increase in users of the Google OS rose from 0.06 to 0.11. Moreover, in 2012 Apple began tying in its search (Siri) and map (Map) OSs. The increase in OS users in 2015 thus produced elasticities of the increase in service users of 0.59 and 0.53 , respectively.

However, while these estimation results are statistically significant, the size of their influence on market competition is not meaningful. The search utilization rate using mobile phones was $66.8 \%$ in 2015 with Google's share of this $35.7 \%$. Moreover, the usage rate for map services was $52.7 \%(70.4 \%)$. A factor explaining this breakdown of market share was the fact that the effects of the complementarity of handset OSs and services were negligible, while the larger share of the service market resulted from the quality of these services themselves.

Concerning the Microsoft issue, the European Commission intervened, unbundling Media Player from Windows and citing standard web browser alternatives with regards to the default settings. However, because of the declining complementarity between the Google OS and its services, despite the intervention to prohibit the pre-installment of a company's own services on its OS, there was a negligible effect on market share. Put another way, although the excess market control of the handset, services, and app markets in the OS market became apparent, the remedies in the services and app markets makes it important to consider plausible interventions besides prohibiting pre-installment.

The framework of the remainder of the paper is as follows. In Section 2, we discuss mobile Internet in the Japanese phone market and the transition to smartphones, which forms the backdrop to the analysis. In Section 3, we examine the Competition Review in the Telecommunications Business Field report used in this analysis as well as the survey data from 2012 and 2015. In Section 4, we present econometric models that use control functions to identify the correlations between complementarity and consumer preferences. In Section 5, we compare the mobile phone OSs for both 2012 and 2015. Lastly, Section 6 contains a conclusion and policy implications.

\section{Migration from feature phones to smartphones in Japan}

\footnotetext{
1 The relationship between the OS and application software/services is often referred to as the "indirect network effect."
} 
In January 1999, NTT DoCoMo, which at the time had the largest number of subscribers in the Japanese market, began to offer the distinctively designed iMode in terms of the OS, handsets, and services. At that point, there were three national carriers and two regional carriers in Japan, with a total of 40 million subscribers. In April 1999, KDDI, which had the second largest number of subscribers, launched its EZWeb service, which conformed to WAP standards ${ }^{2}$. Mobile handsets were provided jointly with the services of the mobile telephone operator. Nakamura (2010) and Ida (2012) point out that because there was no compatibility between mobile phone services in Japan, the switching cost of mobile phone services was high. By April 2000, there were 52 million mobile phone subscribers in Japan, with 9.35 million having contracts for an Internet connection. Mobile Internet utilization then increased suddenly, rising from 27 million users in January 2001 to 48.5 million in January 2002.

The spread of smartphones in the Japanese market began in August 2008 when the SoftBank Group, which at the time had the third largest share of the mobile phone market, was granted an exclusive agreement to launch the iPhone in Japan. See Sinkinson (2014) for the factors leading to the exclusive contracts with AT\&T and Apple. In November 2008, NTT DoCoMo released a Windows Mobile device by HTC Corporation and in July an Android device by the same company. KDDI, which had the second largest number of subscribers, also launched a Windows Mobile device by HTC Corporation in May 2009 and a Sharp Android handset in June 2010 as well as the iPhone in October $2011^{3}$.

When the iPhone was launched in August 2008, the Japanese market comprised four mobile phone carriers; moreover, there were 130 million basic contracts and 89.3 million Internet service contracts with $86.7 \%$ of mobile phone lines used for the Internet. Launches of smartphones loaded with the iPhone and Android OSs by mobile phone carriers increased. By January 2012, the number of mobile phone contracts stood at 122.25 million, with 111.2 million mobile phone Internet contracts, and the market now comprised just three mobile phone carriers ${ }^{4}$. However, the mass migration to iPhone and Android led to a decrease in the number of iMode users.

Besides the three OSs of the Japanese mobile phone carriers, mobile phone OSs were also provided by Google Android, the Apple iPhone, and Microsoft Windows Mobile. All these mobile phone OS providers provided a variety of services (see Figure 1). For example, NTT DoCoMo provided its own OS, Internet mail, search, SNS, eBook, video distribution, online music distribution, app market, electronic payment, cloud storage, and map services to iMode users. Given their nationwide presence, KDDI and SoftBank also offered these services.

Table 1 shows the shares of the services market according to the assessment by the

\footnotetext{
2 These standards were web services created for each mobile phone operator and they involved accessible applications with no handsets or service compatibility between mobile phone carriers.

3 Before the launch of the iPhone by SoftBank, a small mobile phone carrier provided the Windows mobile phone, but this represented only a very small share of the market.

4 Softbank owns three companies that manages three networks by acquisition. In addition to its FDD-LTE network, KDDI owns a subsidiary that manages its TDD-LTE network. These are treated as one company.
} 
Ministry of Internal Affairs and Communications of competition in the telecommunications field. In 2012, NTT DoCoMo's iMode had the largest share of OS users $^{5}$ for mobile phones at 38\%, followed by KDDI's EZWeb at 20.3\% and SoftBank's Yahoo! Ketai at $16.8 \%$, meaning that Japanese OSs made up more than half of all OSs used in the country. Meanwhile, Android's share stood at $12.4 \%$ and iOS had a $6.6 \%$ share.

\section{$<$ Insert Figure 1 $>$ \\ $<$ Insert Table 1>}

According to this same research carried out in 2015, Android had an OS market share of $31.5 \%$ followed by iOS at $22.3 \%$, as the majority of mobile phone users were now using smartphones. The OS share of mobile phone carriers was less, at $20.7 \%, 12.6 \%$, and $10 \%$ for NTT DoCoMo, KDDI, and SoftBank, respectively. Along with fluctuations in OS shares, there were also changes in the services provided; in addition to NTT DoCoMo's exit from the SNS and app markets in February 2015, Google and Apple extended their services. Put simply, both devices and services increasingly transitioned to Android and Apple devices from mobile phone carriers during the study period of $2012-2015^{6}$.

\section{Data}

The data we use in our analysis are taken from the Internet surveys targeting individuals used in the Ministry of Internal Affairs' Competition Review in the Telecommunications Business Field report. Both the 2012 and the 2015 studies were carried out by an Internet survey company in February of those years. The targets of the survey were extracted from entries on the Internet survey company's register, which in turn was created by combining two levels of broadband users from nine regions in Japan. Responses were received from 2,012 individuals in 2012 and 2,124 individuals in 2015, with 1,860 and 1,883 of these respondents being mobile phone users, respectively. Survey items included questions on mobile phone carriers, fee plans, handsets, services, and socioeconomic characteristics ${ }^{7}$.

As shown in Table 1, NTT DoCoMo had the largest market share for handsets and mail in 2012, while SoftBank had the largest share for Internet search services. During the same period, because NTT DoCoMo limited its services provision to its own OS, even for mail and other services with high rates of usage, its services shares were lower than its device shares. Meanwhile, SoftBank offered search, mail, and other services for mobile phones combined with broadband services and provided its services to any mobile OS; its search, mail, and cloud storage shares were therefore greater than its device shares $^{8}$. Google offered its services to all mobile phone OSs and had the largest share for

\footnotetext{
5 These are the OS shares for devices with mobile phone line subscriptions. For devices with line subscriptions, in addition to feature phones, smartphones, and tablet PCs, data transmission devices are also included. The data transmission devices are classified as other OSs.

6 According to the study conducted by the think-tank MM Total Research, in 2014 there were 62.48 million smartphone subscriptions and 61.76 million traditional mobile phone subscriptions, marking the first time that smartphone subscriptions outnumbered feature phone subscriptions.

7 In the case of individuals with multiple subscriptions, we asked for the responses to relate to the line most often used.

8 SoftBank owns Yahoo! JAPAN, which is the most heavily utilized search service for fixed Internet in
} 
videos, the app market, and maps. Apple had the largest share of music-streaming services.

By 2015, Android had 31.5\% of the handset market, while iOS had 22.3\%. NTT DoCoMo saw the market share for the bulk of its services fall, with its mail services, which had the largest market share in 2012, surpassed by SoftBank. SoftBank had the largest share for mail and search services; indeed, even after the widespread migration to smartphones, SoftBank remained a prominent alternative. Google had the largest share for handsets and also continued to have the largest market share for videos, apps, and maps. Indeed, Google showed an increased market share for all of its features. In addition to beginning to provide cloud storage, search, video, and map services, Apple also saw a rise in the market share for all its services other than eBooks. Looked at in chronological order, we found that market share for OS and for services were positively correlated.

Table 2 presents the handsets used the most frequently in 2012 by OS, summarized in rows, while the most frequently used mail services are presented by company in column form. More than $75 \%$ of respondents utilizing the OS of a mobile phone carrier responded that they usually used the mail services of the same carrier. In addition, $15.6 \%$ of Android users responded that they used Google Mail the most. Over half users $(51.2 \%)$ of iOS which did not provide a mail service used a SoftBank mail services, with $21.1 \%$ using a Google mail services. Besides chronological changes, at the same time there was also the correlation between the selection of handset OS and services.

$<$ Insert Table 2>

Table 3 presents the handsets used the most frequently in 2012 by OS, summarized in rows, while the most frequently used search services are presented by company in column form. More than half of respondents using the OS of their mobile phone carriers responded that they usually used the search services of the same carrier. Further, $45.7 \%$ of Android users responded that they used Google's search services the most. Moreover, $44.6 \%$ of iOS users who did not have a search service for mobile phones provided by their carrier were using SoftBank's search services, while 52.9\% were using Google's.

$<$ Insert Table 3>

Table 4 presents the handsets used the most frequently in 2012 by OS, summarized in rows, while the most frequently used map services are presented by company in column form. While the market share for map services by mobile phone carriers was low $(14.1 \%$, $11.1 \%$, and $10.4 \%$ for NTT, KDDI, and SoftBank, respectively), the figures for OS were higher. Indeed, $30.8 \%$ of NTT respondents were using the OS of their mobile phone carrier, while this figure was $55.0 \%$ and $38.0 \%$ for KDDI and SoftBank. Moreover, Google had $50.7 \%$ of the market share for map services. If we limit this to Android users, this figure jumped to $69 \%$.

$<$ Insert Table 4>

Japan. 
One question raised from Tables $2-4$ is why consumers choose services from the same company that provides their handsets. The main two reasons are product complementarity and consumer preferences. First, complementarity exists between devices and services. For example, according to Natsuno (2002), a push mail distribution function explained the success of iMode mail at that time. Similar to receiving phone calls, iMode includes a feature where, when the originator sends an email to iMode users, the iMode mail software which is pre-installed recipient's device is immediately notified through iMode mail server, then the recipient receiving the message right away. When the network, device, and mail service provided by NTT DoCoMo are combined; for the user of an iMode device, iMode mail thus provides a highly convenient service. Moreover, an OS manufacturer often pre-installs its applications as the default setting, while, in the case of Apple, offering browsers and app markets from other companies is prohibited. These factors help produce complementarity between the OS and handset of the same producer that is more effective than a combination of OSs and services from different companies.

Second, consumer preferences for the various differentiated products on the market may be correlated. In addition to evaluating individual products, if consumers have a strong preference for a company that provides more than one product, they may choose other products provided by that company. For example, even without the complementarity between its services, ardent supporters of Google may use their Android phones to access Gmail, conduct Google searches, and use Google Maps, while SoftBank fans may use their Yahoo! Ketai phones to access Yahoo! Mail, conduct Yahoo! Searches, and use Yahoo! Maps.

If the above-described product trends from 2012-2015 resulted from complementarity effects, governmental interventions such as the EU forcing Microsoft to unbundle its application software from its OS should affect the market share for applications and services. On the contrary, if the product trends resulted from consumer preferences, even with an intervention that eliminates complementarity, consumers who choose Android might continue to use Google services. Understanding the driving forces behind the correlation between handsets and services in the mobile phone market is thus beneficial to consider the most effective remedies.

\section{Identification strategy}

This section introduces the identification strategy for understanding the degree of complementarity and consumer preferences in this market. Specifically, we identify those issues that arise when simultaneously deciding on handsets and services by using market price - a variable that affects the choice of handsets but not the choice of services.

\subsection{Consumer choice model}

To examine the choice behavior of consumer $i$ in the mobile phone market, we construct a discrete choice model. Consumer $i(i=1, \ldots, I)$ obtains utility $U_{i j}$ when he or she chooses service $j \in J$. Utility $U_{i j}$ is represented by the function $V\left(x_{i j}, y_{i j}, \beta_{i j}\right)$, which is observable by econometricians. This function contains the variable $x_{i j}$, which affects 
service choice, and the dummy variable $y_{i j}$, which takes the value of one when a device OS was produced by the same company $j$ that provides consumer $i$ 's service, as well as component $\varepsilon_{i j}$, which is unobserved by econometricians. $\beta_{i j}$ represents consumers' preferences for services and has the distribution $\beta \sim N\left(\beta_{0}, \sigma_{\beta}\right)$ for differentiated services. In this case, component $\varepsilon_{i j}$, which is unobserved, might be correlated with $y_{i j}$ because of the unobserved preferences of the consumer. Here, we use the control function approach of Petrin and Train (2010), employing a strategy involving the acquisition of consistent estimators of simultaneous determined issues.

The consumer's choice of handset is represented as $y_{i j}=y\left(z_{i j}, \gamma_{j}\right)+\mu_{i j}$, where the function $y\left(z_{i j}, \gamma_{j}\right)\left(\gamma_{j}\right.$ is a parameter of $\left.z_{i j}\right)$ has the instrumental variable $z_{i j}$, which influences the consumer's device choice $y_{i j}$ but not service choice, as well as $\mu_{i j}$ which is unobserved by econometricians. In this case, if there is a preference for a company not observed by the econometrician, $\mu_{i j}$ is probably correlated with $\varepsilon_{i j}$.

By using the parameter $\lambda$ to express the correlation between $\mu_{i j}$ and $\varepsilon_{i j}$, the unobserved factor of consumer choice on handset $\varepsilon_{i j}$ is able to be replaced with $\varepsilon_{i j}=\lambda \mu_{i j}+\varepsilon_{i j}$, which is the sum of the expected value of $\lambda \mu_{i j}$ conditioned by $\mu_{i j}$ and the divergence $\varepsilon_{i j}$ from the expected value. By replacing the unobserved parts of consumer utility $\varepsilon_{i j}$ for the service choice model, we get $U_{i j}=V\left(x_{i j}, y_{i j}, \beta_{i j}\right)+\lambda \mu_{i j}+\varepsilon_{i j}$. In this case, because $\varepsilon_{i j}$ is not correlated with any other variables, we are able to get consistent estimates by using various regressions.

\subsection{Handset prices}

For the price data, we use the Impress Corporation K-Tai Watch ${ }^{9}$ handset price survey. This survey involves the monthly sales prices of mobile handsets at the Akihabara branch of Yodobashi Camera in Tokyo. Most mobile handsets examined during the study period were bundled with the mobile carrier's services. Handset sales prices varied depending on whether the consumer was new, switching from another service provider, or an existing customer. We use the sales price for new customers.

The survey data from 2012 provide the type of handset used and the period during which the handset was purchased, broken down into seven time periods (less than six months ago, less than a year ago, less than a year and a half ago, less than two years ago, less than three years ago, less than five years ago, and five years or more ago). We use the most recent prices for the handset purchase period provided by respondents.

The survey data from 2015 classified handsets into 38 categories by OS, manufacturer, and compatible networks. We also obtain the same responses as for 2012 with regards to

9 http://k-tai.watch.impress.co.jp/. 
the purchase period for handsets. The OSs consisted of the three OS types related to the mobile phone carriers, Android, iOS, Windows Mobile, and other OSs. Compatible networks included 2G, 3G, 4G (FDD-LTE), and TDD technologies (TD-LTE, WiMAX). Multiple handsets were included in each of these 38 handset categories. We use the average price of those handsets included in the survey that were targeted by the price survey. Table 5 presents the average price and distribution for each handset OS.

$<$ Insert Table 5 $>$

\subsection{Empirical model}

In this section, we discuss the implementation of the empirical model for the handset choice and service choice models. The $y_{i j}$ on the left-hand side of the handset choice model consists of the dummy variable assigned a value of either zero or one depending on the OS of the handset for which the consumer provided answers. For attribute $z_{i j}$, which influences handset choice but is not dependent on service choice, we use the aforementioned handset price. We also use the sex of the consumer, his or her age, the squared value of his or her age, a single person dummy, a residence area dummy, and an income grade dummy as control variables. The aim of the handset choice model is to obtain a consistent estimate of $\mu_{i j}$ that is not correlated with $x_{i j}$ but is correlated with service choice. We then perform a linear regression on $y_{i j}$ by using these variables, obtaining consistent estimates $\hat{\mu}_{i j}$ for $\mu_{i j}{ }^{10}$. Hereafter $\hat{\mu}_{i j}$ is referred to as a control function.

The service choices targeted by this analysis include the mail, search, and map services with high utilization rates for both 2012 and 2015. For 2012, nobody used Apple Mail and Maps, so these were removed from the alternatives. With the 2015 survey, no users of handsets equipped with the Microsoft OS were observed and thus users of the Microsoft OS and services were merged into the other OSs or other services categories, respectively. Seven dependent variables consisting of the services for the five producers excluding Microsoft, other services, and non-use were treated as separate choices for the choice of mail, search, and map services.

For the right-hand side of the service choice model, we employ constant terms indicating the average benefits of the alternatives, the handset utilization dummy $y_{i j}$ that takes the value of one when a handset made by the same service provider is used (indicating complementarity between the service and handset), and the $\hat{\mu}_{i j}$ that is the portion of error term which has correlation with $y_{i j}$ (indicating a correlation with handset choice

\footnotetext{
10 Because handset prices are determined simultaneously by supply and demand, we had to control for price endogeneity and discriminate between supply and demand. Meanwhile, even when we are estimating a demand curve, if countless individuals determine price and product attributes, individual behavior will not affect the market price for handsets. Goldberg (1995) uses properties where individual consumer behavior does not influence market price, estimating individual demand for automobiles by using embedded-type logits as exogenous variables for the market price of automobiles.
} 
$\left.y_{i j}\right)$ as explanatory variables. When integrating multiple services into a single choice, we also combine handsets and services. We standardize the utilities when the applicable service is not utilized to zero.

The $\varepsilon_{i j}$ that is the portion of error term which has no-correlation with handset choice $y_{i j}$ was hypothesized to be an independent and identical (IID) extreme value. The constant terms for the service characteristics, complementarity with handsets, and correlation parameter $\lambda$ were all assumed to have normal distributions. The discrete choice model that contains an IID extreme value error term and the parameters that have distributions over observations were referred to as mixed logit models. We used the RPLOGIT commands of NLOGIT5 to estimate these mixed logit models. Because there was no analytical solution of the likelihood function of these mixed logit models, values were estimated by using the maximum simulated likelihood method, using 300 Halton draws.

The estimated parameters of the service choice model are the constant terms of the alternatives: the average value of the benefits to be gained when the consumer uses mobile phone services with an applicable OS; the coefficient of $y_{i j}$, which represents the complementarity of handset and services; and the coefficient of the control function $\hat{\mu}_{i j}$, which the strength of the correlation of the unobserved portion of consumer choice with regards to the choice of services and handsets. In other words, the estimated equations for the service choice formula and handset choice formula are given as

$$
\begin{gathered}
u_{i j}=\alpha_{i j}+\beta_{i} y_{i j}+\lambda \hat{\mu}_{i j}+\varepsilon_{i j} \\
y_{i j}=\phi_{j}+z_{i j} \gamma_{j}+x_{j} \delta+\mu_{i j}
\end{gathered}
$$

\section{Empirical results}

Based on the estimates from Equations (1) and (2), in this section, we assess the estimation results of the service choice model for 2012 and 2015. In particular, we analyze the elasticities for whether handset choice affects service choice and note changes in the estimation results between 2012 and 2015 as well as the policy implications gained from this ${ }^{11}$.

\subsection{Empirical results in 2012}

Table 6 summarizes the estimation results for the service choice model of 2012. Recall that the subjects of the analysis are mail, search, and map services with high rates of utilization. The options consisted of the three services offered by the mobile phone

\footnotetext{
11 We attempted an analysis similar to that of 2012 for the app market and cloud storage and for the payment, music, cloud storage, and app market of 2015. However, because there were a limited number of end-users, few services had independent alternatives, and there were no direct comparable parameters between 2012 and 2015. Hence, we excluded these from the analysis. These estimated results as well as elasticities are noted in Tables A4-A7 of the Appendix.
} 
carriers as well as Google, Microsoft, and other companies, and finally non-use. No services were offered by Apple, so Apple was not included in the alternatives. The coefficient of $y_{i j}$ indicates complementarity between the handset and services, with a statistically significant positive complementarity existing for the mail, search, and map services. Moreover, the control function $\hat{\mu}_{i j}$ is positively significant for mail but negatively significant for search and maps. The service choice for mail is positively affected by the complementarity and customer preference correlations. However, despite the positive complementarity, the preference correlation was negative for search and map services.

\section{$<$ Insert Table 6>}

Table 7 presents the elasticities of service choice to handset choice, which indicate the extent to which the use of mail, search, or map services increases by a $1 \%$ increase in handset choice probability. For Google, which had the highest handset elasticity for mail services, the elasticity was 0.079 , while Microsoft had the lowest elasticity at 0.0029 . Moreover, for search services, NTT had the highest elasticity at 0.4736 , while Microsoft had the lowest elasticity at 0.0126 . For map services, KDDI had the highest elasticity at 0.3699 , while the other services category was the lowest at $0.0023^{12}$. KDDI started installing GPS on its devices before any other telecommunications carrier; the fact that it offered a navigation application may have driven the high level of complementarity. In 2012, the complementarity between handsets and services significantly influenced the use of mail, search, and map services. Android contributed to Gmail's increased market share, while the mobile phone carrier OSs increased market share for search and maps.

\section{$<$ Insert Table 7>}

\subsection{Empirical results in 2015}

Table 8 presents the estimation results for the 2015 choice model for mail, search, and map services. Here, Microsoft was included within other alternatives. Mail, search, and map services showed significant complementarity between handsets and services. Moreover, a significant positive preference correlation was obtained for mail compared with a significant negative correlation for search and maps.

\section{$<$ Insert Table 8>}

Table 9 shows the elasticities of service choice to handset choice. In 2015, NTT mail had a significant positive elasticity (0.0006), while SoftBank had a significant negative elasticity (-0.0052). Meanwhile, Google and Apple continued to experience significant positive elasticities (0.0949 and 0.2980, respectively). For search services, all companies exhibited significant positive elasticities. This was particularly true of Apple, which had a very high elasticity (0.5851), although Google and SoftBank had low elasticities (0.1059 and 0.0042, respectively). For map services, Apple had a high elasticity of 0.5300 .

\footnotetext{
12 The $y_{i j}$ for other companies was always 0 . This elasticity was for the counterfactual situation when a carrier providing temporary services ended up providing the handset OS.
} 
For mail, the 2015 handset OS had the effect of expanding Google's (market) share, while the complementarity that Apple enjoyed with its handset led to its successful entry into mail, search, and map services.

\section{$<$ Insert Table 9>}

Let us next compare the estimation results for 2012 and 2015. The elasticity for services provided by the mobile phone carriers fell between 2012 and 2015. The elasticity for Google's mail and search services also fell, but Google Maps saw an increase in elasticity. By entering the mail, search, and map services markets, Apple experienced a significant positive elasticity. Put another way, in 2012, the three OSs of the mobile phone carriers benefitted from complementarity more than the smartphone OSs; however, in 2015, the complementarity effects of the mobile phone carriers' OSs and services weakened and smartphone OSs seized market share in the services area.

In markets where the complementarity between OS and software played an important role in product demand, various strategic actions were taken to resolve this "chicken and egg" problem. However, by increasing their services, Google and Apple were able to successfully take market share away from the existing mobile phone carriers in all service areas. This increase in market share for services for Google and Apple was largely dependent on the quality of their products and services. Hence, the relationship between services and OSs served to leverage market share in services to the OS market, rather than leveraging OS market control for use in the services market.

\section{Conclusion}

Given the concern of excessive market control in the mobile phone OS market, the present study analyzed the extent to which OSs affect market share in the services market. The results of this analysis showed that for mail, search, and maps services, there was significant positive complementarity between OSs and services. However, from our analysis of elasticity, rather than OSs acting to leverage growth in the market share of the services market, services were acting to leverage growth in the market share of the OS market. Moreover, in 2012, the complementarity between handsets and OSs contributed to increased market share for mobile phone carriers in the services market, but by 2015 , this contributed to increased services market share for Google and Apple through the provision of their smartphone OSs.

Complementary products such as handsets and services are frequently cited as having indirect network effects. Indeed, with an extensive range of complementary products, there is concern that market entry will be difficult. However, the dominant position of OSs and applications as established by mobile phone carriers has been superseded by high-quality services and a complementary OS.

With Europe taking the lead, the competition authorities of the United States and Japan are keenly interested in Google's anti-competitive behavior. However, the effect of handset on the service market where market power is leveraged is limited. Further, besides ordering Microsoft to provide an OS where Media Player has been jettisoned, the 
European Commission has also consented to making it possible to select another company's browser as the default setting. Assuming that the OS and application software separation could be carried out for a given service market, this might have the effect of diminishing the market share for mail, search, and maps which possess significant interpolation with OSs. However, because the handset elasticity of service is rather small, the expected effects are minimal. The competition authorities should thus pay close attention to abuses in market power in the services market.

Meanwhile, there is no settled opinion concerning how to treat multi-sided market competition that does not involve direct compensation from consumers, such as for search and map services. Rochet and Tirole's (2008) claims that an intervention should be made only under clear inefficiency in the market and when there are effective remedies may be too timid. However, the inefficiency of less effective governmental interventions remains a problem. More research thus needs to be conducted on what form effective intervention in the Internet service market should take. 


\section{Reference}

[1] Carlton, D. W., Gans, J. S., \& Waldman, M. (2010). Why Tie a Product Consumers Do Not Use?. American Economic Journal: Microeconomics, 2(3), 85-105. doi:http://dx.doi.org/10.1257/mic.2.3.85

[2] Choi, J. P., \& Stefanadis, C. (2001). Tying, Investment, and the Dynamic Leverage Theory. RAND Journal Of Economics, 32(1), 52-71.

[3] Gilbert, R. J., \& Katz, M. L. (2001). An Economist's Guide to U.S. v. Microsoft. Journal Of Economic Perspectives, 15(2), 25-44. doi:http://dx.doi.org/10.1257/jep.15.2.25

[4] Goldberg, P. K. (1995). Product Differentiation and Oligopoly in International Markets: The Case of the U.S. Automobile Industry. Econometrica, 63(4), 891951.

[5] Ida, T. (2012). Beyond Mobile Number Portability: Measuring Consumer Preferences for Service Portability in Japan's Mobile Phone Market. Applied Economics, 44(25-27), 3357-3369.

[6] Klein, B. (2001). The Microsoft Case: What Can a Dominant Firm Do to Defend Its Market Position?. Journal Of Economic Perspectives, 15(2), 45-62. doi:http://dx.doi.org/10.1257/jep.15.2.45

[7] Nalebuff, B. (2004). Bundling as an Entry Barrier. Quarterly Journal Of Economics, $119(1), 159-187$.

[8] Nakamura, A. (2010). Estimating Switching Costs Involved in Changing Mobile Phone Carriers in Japan: Evaluation of Lock-In Factors Related to Japan's SIM Card Locks. Telecommunications Policy, 34(11), 736-746. doi:http://dx.doi.org/10.1016/j.telpol.2010.10.003

[9] Natsuno, T. (2002) A la i-mode, Nikkei Business Publications.

[10] Petrin, A., \& Train, K. (2010). A Control Function Approach to Endogeneity in Consumer Choice Models. Journal Of Marketing Research, 47(1), 3-13.

[11] Posner, R. (1976) Antitrust Law: An Economic Perspective. Chicago: University of Chicago Press.

[12] Sinkinson, M. (2014) Pricing and Entry Incentives with Exclusive Contracts: Evidence from Smartphones. Available at SSRN: https://ssrn.com/abstract=2391745 or http://dx.doi.org/10.2139/ssrn.2391745

[13] Rochet, J., \& Tirole, J. (2008). Competition Policy in Two-Sided Markets, with a Special Emphasis on Payment Cards. In P. Buccirossi (Ed.), Handbook of Antitrust Economics (pp. 543-582). Cambridge and London: MIT Press.

[14] Whinston, M. D. (1990). Tying, Foreclosure, and Exclusion. American Economic Review, 80(4), 837-859.

[15] Whinston, M. D. (2001). Exclusivity and Tying in U.S. v. Microsoft: What We Know, and Don't Know. Journal Of Economic Perspectives, 15(2), 63-80. doi:http://dx.doi.org/10.1257/jep.15.2.63 
Table 1. Market shares of the OSs and services.

\begin{tabular}{|c|c|c|c|c|c|c|c|c|c|c|c|}
\hline & OS & Mail & Search & SNS & Book & Movie & Music & App & Payment & Cloud & Map \\
\hline \multicolumn{12}{|l|}{2012} \\
\hline Usage rates & $100.0 \%$ & $85.4 \%$ & $59.6 \%$ & $25.1 \%$ & $0.6 \%$ & $24.2 \%$ & $12.7 \%$ & $16.1 \%$ & $26.5 \%$ & $5.5 \%$ & $31.6 \%$ \\
\hline NTT & $38.0 \%$ & $34.8 \%$ & $19.8 \%$ & $1.6 \%$ & $2.0 \%$ & $0.0 \%$ & $1.9 \%$ & $4.3 \%$ & $27.4 \%$ & $2.5 \%$ & $14.1 \%$ \\
\hline KDDI & $20.3 \%$ & $19.0 \%$ & $9.7 \%$ & $0.0 \%$ & $2.6 \%$ & $0.3 \%$ & $8.0 \%$ & $5.0 \%$ & $14.5 \%$ & $0.0 \%$ & $11.1 \%$ \\
\hline SoftBank & $16.8 \%$ & $26.9 \%$ & $41.4 \%$ & $0.0 \%$ & $4.6 \%$ & $0.0 \%$ & $0.0 \%$ & $9.5 \%$ & $9.0 \%$ & $20.2 \%$ & $10.4 \%$ \\
\hline Google & $12.4 \%$ & $6.0 \%$ & $26.7 \%$ & $1.6 \%$ & $0.0 \%$ & $82.6 \%$ & $0.0 \%$ & $40.6 \%$ & $0.0 \%$ & $16.1 \%$ & $50.7 \%$ \\
\hline Apple & $6.6 \%$ & $0.0 \%$ & $0.0 \%$ & $0.0 \%$ & $7.9 \%$ & $0.0 \%$ & $54.5 \%$ & $37.2 \%$ & $3.8 \%$ & $26.0 \%$ & $0.0 \%$ \\
\hline Microsoft & $0.5 \%$ & $2.3 \%$ & $0.8 \%$ & $0.0 \%$ & $0.0 \%$ & $0.0 \%$ & $0.0 \%$ & $0.2 \%$ & $0.0 \%$ & $6.2 \%$ & $0.3 \%$ \\
\hline Others & $5.3 \%$ & $11.0 \%$ & $1.6 \%$ & $96.7 \%$ & $82.8 \%$ & $17.1 \%$ & $35.6 \%$ & $3.2 \%$ & $45.4 \%$ & $28.9 \%$ & $13.4 \%$ \\
\hline Share Total & $100.0 \%$ & $100.0 \%$ & $100.0 \%$ & $100.0 \%$ & $100.0 \%$ & $100.0 \%$ & $100.0 \%$ & $100.0 \%$ & $100.0 \%$ & $100.0 \%$ & $100.0 \%$ \\
\hline \multicolumn{12}{|l|}{2015} \\
\hline Usage rates & $100.0 \%$ & $93.3 \%$ & $66.8 \%$ & $47.1 \%$ & $16.0 \%$ & $48.4 \%$ & $26.2 \%$ & $44.2 \%$ & $36.0 \%$ & $24.6 \%$ & $52.7 \%$ \\
\hline NTT & $20.7 \%$ & $26.2 \%$ & $11.2 \%$ & $0.0 \%$ & $4.3 \%$ & $1.3 \%$ & $3.9 \%$ & $0.0 \%$ & $18.6 \%$ & $1.7 \%$ & $9.2 \%$ \\
\hline KDDI & $12.6 \%$ & $16.9 \%$ & $4.8 \%$ & $0.0 \%$ & $0.3 \%$ & $0.2 \%$ & $3.0 \%$ & $2.4 \%$ & $16.4 \%$ & $5.0 \%$ & $4.6 \%$ \\
\hline SoftBank & $10.0 \%$ & $27.1 \%$ & $43.0 \%$ & $0.0 \%$ & $2.6 \%$ & $0.0 \%$ & $0.0 \%$ & $1.1 \%$ & $7.7 \%$ & $11.9 \%$ & $5.6 \%$ \\
\hline Google & $31.5 \%$ & $14.7 \%$ & $35.7 \%$ & $1.9 \%$ & $9.6 \%$ & $86.7 \%$ & $13.6 \%$ & $47.7 \%$ & $1.2 \%$ & $22.2 \%$ & $70.4 \%$ \\
\hline Apple & $22.3 \%$ & $0.8 \%$ & $1.9 \%$ & $0.0 \%$ & $4.3 \%$ & $0.8 \%$ & $63.1 \%$ & $45.3 \%$ & $5.9 \%$ & $27.9 \%$ & $3.4 \%$ \\
\hline Microsoft & $0.0 \%$ & $4.0 \%$ & $0.4 \%$ & $0.0 \%$ & $0.0 \%$ & $0.0 \%$ & $0.4 \%$ & $0.5 \%$ & $0.0 \%$ & $6.3 \%$ & $0.3 \%$ \\
\hline Others & $2.9 \%$ & $10.2 \%$ & $3.0 \%$ & $98.1 \%$ & $78.8 \%$ & $11.0 \%$ & $16.0 \%$ & $3.0 \%$ & $50.3 \%$ & $25.1 \%$ & $6.5 \%$ \\
\hline Share Total & $100.0 \%$ & $100.0 \%$ & $100.0 \%$ & $100.0 \%$ & $100.0 \%$ & $100.0 \%$ & $100.0 \%$ & $100.0 \%$ & $100.0 \%$ & $100.0 \%$ & $100.0 \%$ \\
\hline
\end{tabular}


Table 2. The share of mail services used the most frequently in 2012 by OS

\begin{tabular}{|c|c|c|c|c|c|c|c|c|c|c|}
\hline & \multirow{2}{*}{$\begin{array}{c}\text { Handset } \\
\text { OS } \\
\text { Shares }\end{array}$} & \multirow{2}{*}{$\begin{array}{l}\text { Mail } \\
\text { Shares }\end{array}$} & \multicolumn{8}{|c|}{ Mail services (within each handset OS) } \\
\hline & & & NTT & KDDI & SoftBank & Google & Apple & Microsoft & Others & Share Total \\
\hline NTT & $38.0 \%$ & $34.8 \%$ & $76.6 \%$ & $0.0 \%$ & $9.4 \%$ & $1.7 \%$ & $0.0 \%$ & $2.5 \%$ & $9.9 \%$ & $100.0 \%$ \\
\hline KDDI & $20.3 \%$ & $19.0 \%$ & $0.0 \%$ & $78.7 \%$ & $8.6 \%$ & $3.2 \%$ & $0.0 \%$ & $1.4 \%$ & $8.1 \%$ & $100.0 \%$ \\
\hline SoftBank & $16.8 \%$ & $26.9 \%$ & $1.4 \%$ & $0.0 \%$ & $81.5 \%$ & $3.5 \%$ & $0.0 \%$ & $2.4 \%$ & $11.1 \%$ & $100.0 \%$ \\
\hline Google & $12.4 \%$ & $6.0 \%$ & $35.9 \%$ & $18.2 \%$ & $19.5 \%$ & $15.6 \%$ & $0.0 \%$ & $1.3 \%$ & $9.5 \%$ & $100.0 \%$ \\
\hline Apple & $6.6 \%$ & $0.0 \%$ & $2.4 \%$ & $4.1 \%$ & $51.2 \%$ & $21.1 \%$ & $0.0 \%$ & $4.9 \%$ & $16.3 \%$ & $100.0 \%$ \\
\hline Microsoft & $0.5 \%$ & $2.3 \%$ & $22.2 \%$ & $0.0 \%$ & $44.4 \%$ & $11.1 \%$ & $0.0 \%$ & $11.1 \%$ & $11.1 \%$ & $100.0 \%$ \\
\hline Others & $5.3 \%$ & $11.0 \%$ & $17.2 \%$ & $11.8 \%$ & $32.3 \%$ & $10.8 \%$ & $0.0 \%$ & $2.2 \%$ & $25.8 \%$ & $100.0 \%$ \\
\hline Share Total & $100.0 \%$ & $100.0 \%$ & & & & & & & & \\
\hline
\end{tabular}


Table 3. The share of search services used the most frequently in 2012 by OS

\begin{tabular}{|c|c|c|c|c|c|c|c|c|c|c|}
\hline & \multirow{2}{*}{$\begin{array}{c}\text { Handset } \\
\text { OS } \\
\text { Shares }\end{array}$} & \multirow{2}{*}{$\begin{array}{l}\text { Search } \\
\text { Shares }\end{array}$} & \multicolumn{8}{|c|}{ Search services (within each handset OS) } \\
\hline & & & NTT & KDDI & SoftBank & Google & Apple & Microsoft & Others & Share Total \\
\hline NTT & $38.0 \%$ & $19.8 \%$ & $50.9 \%$ & $0.0 \%$ & $29.7 \%$ & $17.8 \%$ & $0.0 \%$ & $0.5 \%$ & $1.1 \%$ & $100.0 \%$ \\
\hline KDDI & $20.3 \%$ & $9.7 \%$ & $0.5 \%$ & $50.5 \%$ & $29.4 \%$ & $18.2 \%$ & $0.0 \%$ & $0.5 \%$ & $0.9 \%$ & $100.0 \%$ \\
\hline SoftBank & $16.8 \%$ & $41.4 \%$ & $1.7 \%$ & $0.0 \%$ & $85.7 \%$ & $10.9 \%$ & $0.0 \%$ & $0.6 \%$ & $1.1 \%$ & $100.0 \%$ \\
\hline Google & $12.4 \%$ & $26.7 \%$ & $6.7 \%$ & $4.5 \%$ & $41.3 \%$ & $45.7 \%$ & $0.0 \%$ & $0.9 \%$ & $0.9 \%$ & $100.0 \%$ \\
\hline Apple & $6.6 \%$ & $0.0 \%$ & $0.8 \%$ & $0.0 \%$ & $44.6 \%$ & $52.9 \%$ & $0.0 \%$ & $0.0 \%$ & $1.7 \%$ & $100.0 \%$ \\
\hline Microsoft & $0.5 \%$ & $0.8 \%$ & $12.5 \%$ & $0.0 \%$ & $37.5 \%$ & $50.0 \%$ & $0.0 \%$ & $0.0 \%$ & $0.0 \%$ & $100.0 \%$ \\
\hline Others & $5.3 \%$ & $1.6 \%$ & $5.3 \%$ & $5.3 \%$ & $36.8 \%$ & $38.2 \%$ & $0.0 \%$ & $5.3 \%$ & $9.2 \%$ & $100.0 \%$ \\
\hline Share Total & $100.0 \%$ & $100.0 \%$ & & & & & & & & \\
\hline
\end{tabular}


Table 4. The share of map services used the most frequently in 2015 by OS

\begin{tabular}{|c|c|c|c|c|c|c|c|c|c|c|}
\hline & \multirow{2}{*}{$\begin{array}{c}\text { Handset } \\
\text { OS } \\
\text { Shares }\end{array}$} & \multirow{2}{*}{$\begin{array}{l}\text { Map } \\
\text { Shares }\end{array}$} & \multicolumn{8}{|c|}{ Map services (within each handset OS) } \\
\hline & & & NTT & KDDI & SoftBank & Google & Apple & Microsoft & Others & Share Total \\
\hline NTT & $38.0 \%$ & $14.1 \%$ & $30.8 \%$ & $0.0 \%$ & $8.0 \%$ & $42.3 \%$ & $0.0 \%$ & $0.0 \%$ & $18.9 \%$ & $100.0 \%$ \\
\hline KDDI & $20.3 \%$ & $11.1 \%$ & $5.8 \%$ & $55.0 \%$ & $6.7 \%$ & $22.5 \%$ & $0.0 \%$ & $0.0 \%$ & $10.0 \%$ & $100.0 \%$ \\
\hline SoftBank & $16.8 \%$ & $10.4 \%$ & $5.6 \%$ & $1.4 \%$ & $38.0 \%$ & $39.4 \%$ & $0.0 \%$ & $0.0 \%$ & $15.5 \%$ & $100.0 \%$ \\
\hline Google & $12.4 \%$ & $50.7 \%$ & $10.9 \%$ & $5.4 \%$ & $6.0 \%$ & $69.0 \%$ & $0.0 \%$ & $0.0 \%$ & $8.7 \%$ & $100.0 \%$ \\
\hline Apple & $6.6 \%$ & $0.0 \%$ & $5.8 \%$ & $1.0 \%$ & $7.8 \%$ & $68.9 \%$ & $0.0 \%$ & $1.0 \%$ & $15.5 \%$ & $100.0 \%$ \\
\hline Microsoft & $0.5 \%$ & $0.3 \%$ & $16.7 \%$ & $0.0 \%$ & $0.0 \%$ & $66.7 \%$ & $0.0 \%$ & $0.0 \%$ & $16.7 \%$ & $100.0 \%$ \\
\hline Others & $5.3 \%$ & $13.4 \%$ & $6.7 \%$ & $6.7 \%$ & $13.3 \%$ & $62.2 \%$ & $0.0 \%$ & $2.2 \%$ & $8.9 \%$ & $100.0 \%$ \\
\hline Share Total & $100.0 \%$ & $100.0 \%$ & & & & & & & & \\
\hline
\end{tabular}


Table 5. Average and distribution of handset prices.

\begin{tabular}{ccc}
\hline \hline \multicolumn{2}{c}{ Handset Price (JPY) } \\
\hline & Mean & Std.Dev. \\
\hline $\mathbf{2 0 1 2}$ & \\
\hline NTT & 24471 & 25195 \\
KDDI & 20726 & 22771 \\
SoftBank & 29546 & 37138 \\
Google & 56464 & 16666 \\
Apple & 63676 & 5684.9 \\
Microsoft & 59876 & 14610 \\
Others & 18352 & 23098 \\
\hline Total & 31246 & 29122 \\
\hline \hline 2015 & & \\
\hline NTT & 31137 & 5897.9 \\
KDDI & 30129 & 2329.7 \\
SoftBank & 36564 & 4177.6 \\
Google & 61361 & 16197 \\
Apple & 64553 & 17459 \\
Others & 20847 & 25092 \\
\hline Total & 48143 & 20705 \\
\hline \hline
\end{tabular}


Table 6. The estimation results for the service choice model of 2012.

\begin{tabular}{|c|c|c|c|c|c|c|c|c|c|}
\hline & \multicolumn{3}{|l|}{ Mail } & \multicolumn{3}{|l|}{ Search } & \multicolumn{3}{|l|}{ Map } \\
\hline \multicolumn{3}{|c|}{ Log likelihood function } & -2304.9 & & & -2530.6 & & & -2027.8 \\
\hline \multicolumn{3}{|c|}{ McFadden Pseudo R-squared } & 0.3662 & & & 0.30419 & & & 0.44243 \\
\hline & \multicolumn{2}{|l|}{ Mean } & S.E & \multicolumn{2}{|l|}{ Mean } & S.E & \multicolumn{2}{|l|}{ Mean } & S.E \\
\hline NTT & 1.6453 & $* *$ & 0.81861 & -3.7161 & $* * *$ & 0.41063 & -283.94 & $* * *$ & 19.379 \\
\hline KDDI & 0.5590 & & 0.37211 & -3.9140 & $* * *$ & 0.27836 & -16.434 & $* * *$ & 4.1801 \\
\hline SoftBank & 2.0332 & $* * *$ & 0.68441 & -2.8646 & $* * *$ & 0.94582 & -70.323 & $* * *$ & 23.501 \\
\hline Google & -119.98 & $* * *$ & 27.1671 & -1.0986 & $* * *$ & 0.08830 & -1.8817 & $* * *$ & 0.1310 \\
\hline Microsoft & -35.077 & $* * *$ & 12.4335 & -16.724 & $* *$ & 6.5182 & -305.89 & & 952.05 \\
\hline Others & -114.71 & $* * *$ & 21.1916 & -8.4797 & $* * *$ & 1.5657 & -713.89 & $* * *$ & 22.102 \\
\hline$y_{i j}$ & 22.309 & $* * *$ & 5.56595 & 3.5881 & $* * *$ & 0.55794 & 7.6624 & $* * *$ & 1.2288 \\
\hline \multirow[t]{2}{*}{$\hat{\mu}_{i j}$} & 10.118 & $* * *$ & 1.45351 & -1.9847 & $* * *$ & 0.36774 & -3.8304 & $* * *$ & 0.4232 \\
\hline & \multicolumn{2}{|l|}{ Std.Dev } & S.E & \multicolumn{2}{|l|}{ Std.Dev } & 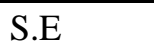 & Std.Dev & \multicolumn{2}{|r|}{ S.E } \\
\hline NTT & 4.5265 & $* * *$ & 1.1170 & 0.6877 & & 0.66761 & 181.35 & $* * *$ & 10.836 \\
\hline KDDI & 0.1259 & & 1.3800 & 0.0351 & & 1.0107 & 7.2655 & $* * *$ & 2.1047 \\
\hline SoftBank & 7.2878 & $* * *$ & 2.3955 & 5.2445 & $* * *$ & 1.6485 & 41.762 & $* * *$ & 13.905 \\
\hline Google & 85.336 & $* * *$ & 18.565 & 0.0833 & & 0.30474 & 0.1528 & & 0.9122 \\
\hline Microsoft & 24.615 & $* * *$ & 7.9353 & 6.9631 & $* *$ & 2.8047 & 112.89 & & 338.47 \\
\hline Others & 108.67 & $* * *$ & 19.369 & 3.4544 & $* * *$ & 0.83183 & 447.80 & $* * *$ & 12.593 \\
\hline$y_{i j}$ & 35.747 & $* * *$ & 7.6896 & 4.2012 & $* * *$ & 1.0530 & 9.6321 & $* * *$ & 2.7728 \\
\hline$\hat{\mu}_{i j}$ & 2.2503 & & 1.8275 & 0.0903 & & 0.44605 & 0.2449 & & 1.9177 \\
\hline
\end{tabular}

Note: $* * *, * *, *$ mean significances at $1 \%, 5 \%, 10 \%$ level by $\mathrm{Z}$ statistics. 
Table 7. The elasticities of mail, search, and map services of 2012.

\begin{tabular}{lclllll}
\hline \multicolumn{2}{c}{ Mail } & \multicolumn{3}{c}{ Search } & \multicolumn{1}{c}{ Map } \\
\hline \hline NTT & 0.0278 & $* * *$ & 0.4736 & $* * *$ & 0.0451 & $* * *$ \\
KDDI & 0.0113 & $* * *$ & 0.2963 & $* * *$ & 0.3699 & $* * *$ \\
SoftBank & 0.0036 & $* * *$ & 0.0898 & $* * *$ & 0.0881 & $* * *$ \\
Google & 0.0791 & $* * *$ & 0.0563 & $* * *$ & 0.0310 & $* * *$ \\
Microsoft & 0.0029 & $* *$ & 0.0126 & $* * *$ & 0.0252 & $* *$ \\
Others & 0.0201 & $* * *$ & 0.1234 & $* * *$ & 0.0023 & $* *$ \\
\hline \hline
\end{tabular}

Note: ***,**,* mean significances at $1 \%, 5 \%, 10 \%$ level by $\mathrm{Z}$ statistics. 
Table 8. The estimation results for the service choice model of 2015.

\begin{tabular}{|c|c|c|c|c|c|c|c|c|c|}
\hline & \multicolumn{3}{|l|}{ Mail } & \multicolumn{3}{|l|}{ Search } & \multicolumn{3}{|l|}{ Map } \\
\hline \multicolumn{3}{|c|}{ Log likelihood function } & $2762.7^{-}$ & & & -2641.7 & & & -2070.8 \\
\hline \multicolumn{3}{|c|}{ McFadden Pseudo R-squared } & 0.2420 & & & 0.2752 & & & 0.4318 \\
\hline & Mean & & S.E & Mean & & S.E & \multicolumn{2}{|l|}{ Mean } & S.E \\
\hline NTT & 0.9249 & $* *$ & 0.3905 & -22.726 & $* * *$ & 6.3430 & -261.14 & $* *$ & 121.46 \\
\hline KDDI & -3.6526 & $* *$ & 1.8538 & -19.404 & $* * *$ & 5.2755 & -63.712 & $* *$ & 30.452 \\
\hline SoftBank & 2.2932 & $* * *$ & 0.3834 & -104.25 & $* * *$ & 13.860 & -100.63 & & 71.189 \\
\hline Google & -98.881 & $* * *$ & 17.604 & -1.6468 & $* * *$ & 0.12276 & -1.9233 & $* * *$ & 0.27023 \\
\hline Apple & -78.754 & $* * *$ & 19.409 & -17.551 & $* *$ & 7.1140 & -34.292 & $* *$ & 16.615 \\
\hline Others & -114.71 & $* * *$ & 21.420 & -190.25 & $* * *$ & 45.950 & -286.43 & $* *$ & 144.93 \\
\hline$y_{i j}$ & 13.312 & $* * *$ & 3.8029 & 6.7298 & $* * *$ & 1.0506 & 9.6586 & $* * *$ & 2.9156 \\
\hline \multirow[t]{2}{*}{$\hat{\mu}_{i j}$} & 11.606 & $* * *$ & 2.4211 & -4.1570 & $* * *$ & 0.38524 & -5.6574 & $* * *$ & 0.8455 \\
\hline & Std.Dev & & S.E & Std.Dev & & S.E & Std.Dev & & S.E \\
\hline NTT & 2.5794 & $* *$ & 1.0394 & 17.260 & $* * *$ & 4.8372 & 159.34 & $* *$ & 73.854 \\
\hline KDDI & 7.0961 & $* * *$ & 2.2880 & 11.098 & $* * *$ & 3.1528 & 34.907 & $* *$ & 16.735 \\
\hline SoftBank & 1.3626 & & 1.1077 & 184.06 & $* * *$ & 23.5136 & 56.036 & & 38.907 \\
\hline Google & 97.135 & $* * *$ & 16.361 & 0.1276 & & 0.42010 & 0.3451 & & 1.0775 \\
\hline Apple & 36.816 & $* * *$ & 9.1690 & 6.9794 & $*$ & 3.7670 & 14.335 & $* *$ & 7.0872 \\
\hline Others & 117.19 & $* * *$ & 20.785 & 108.46 & $* * *$ & 25.835 & 165.12 & $* *$ & 83.055 \\
\hline$y_{i j}$ & 25.552 & $* * *$ & 4.9220 & 8.2607 & $* * *$ & 2.5396 & 14.201 & $* *$ & 6.9607 \\
\hline$\hat{\mu}_{i j}$ & 0.4797 & & 1.9082 & 0.9538 & & 1.1525 & 1.6404 & & 1.4670 \\
\hline
\end{tabular}

Note: ***,**, * mean significances at $1 \%, 5 \%, 10 \%$ level by $\mathrm{Z}$ statistics. 
Table 9. The elasticities of mail, search, and map services of 2015.

\begin{tabular}{lrlrlrl}
\hline \multicolumn{2}{c}{ Mail } & \multicolumn{3}{c}{ Search } & \multicolumn{1}{l}{ Map } \\
\hline \hline NTT & 0.0006 & 0.1763 & $* * *$ & 0.0355 & $* * *$ \\
KDDI & 0.0052 & $* * *$ & 0.1829 & $* * *$ & 0.1301 & $* * *$ \\
SoftBank & -0.0052 & $* * *$ & 0.0042 & $* * *$ & 0.0552 & $* * *$ \\
Google & 0.0949 & $* * *$ & 0.1059 & $* * *$ & 0.0738 & $* * *$ \\
Apple & 0.2980 & $* * *$ & 0.5851 & $* * *$ & 0.5300 & $* * *$ \\
Others & 0.0078 & $* * *$ & 0.0043 & $* *$ & 0.0049 & $* *$ \\
\hline \hline
\end{tabular}

Note: ***,**,* mean significances at $1 \%, 5 \%, 10 \%$ level by $\mathrm{Z}$ statistics. 
Figure 1.

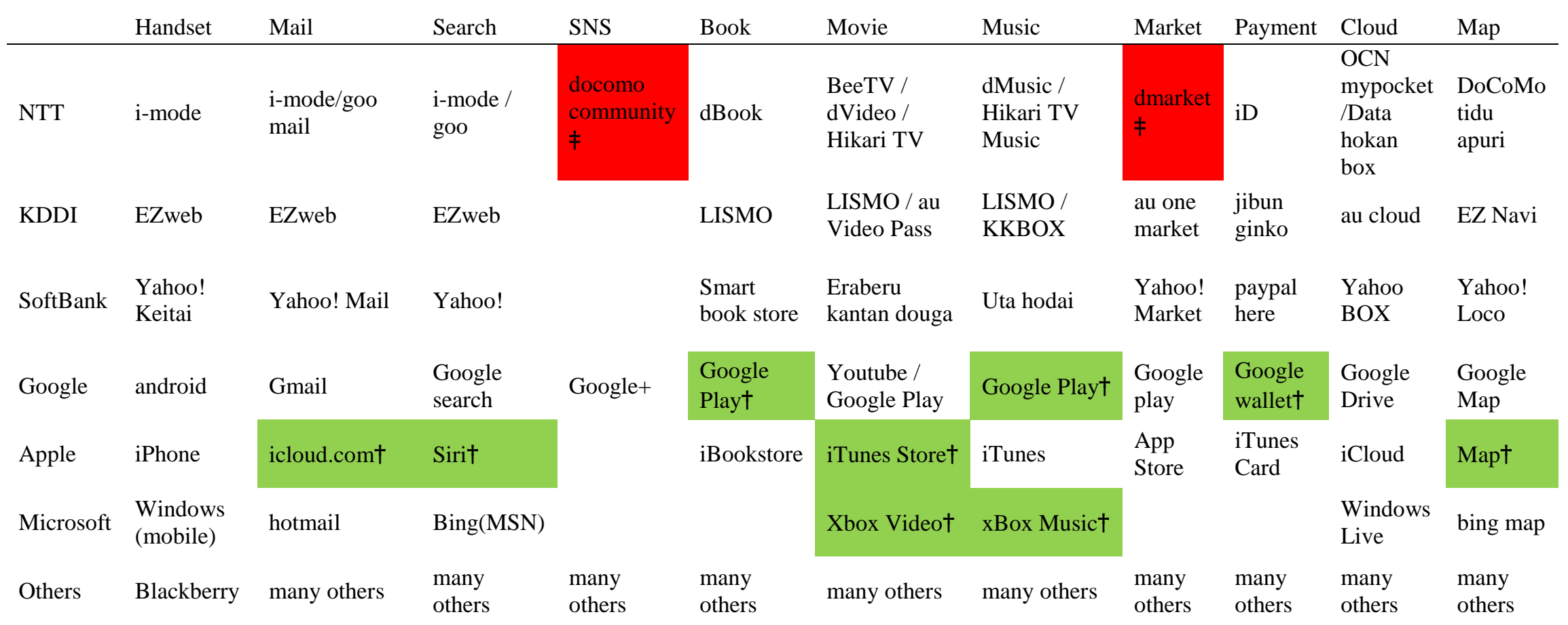

Note: $†$ represents entry since 2011. ‡erepresents exit by 2014 .

Note: Some service name changed from 2011 to 2014. We use name at 2014. 
APPENDIX

Table A1 Summary statistics of individual characteristics over handset OS

\begin{tabular}{|c|c|c|c|c|c|c|c|}
\hline & \multicolumn{4}{|c|}{$\operatorname{Sex}(\operatorname{men}=1)$} & Age & \multicolumn{2}{|l|}{ Single } \\
\hline & Observations & Mean & Std.Dev. & Mean & Std.Dev. & Mean & Std.Dev. \\
\hline \multicolumn{8}{|l|}{2012} \\
\hline NTT & 711 & 0.6301 & 0.4831 & 45.91 & 11.26 & 0.3333 & 0.4717 \\
\hline KDDI & 380 & 0.6553 & 0.4759 & 46.24 & 10.33 & 0.3368 & 0.4733 \\
\hline SoftBank & 314 & 0.6401 & 0.4807 & 46.64 & 11.10 & 0.2866 & 0.4529 \\
\hline Google & 232 & 0.7672 & 0.4235 & 40.59 & 9.91 & 0.3621 & 0.4816 \\
\hline Apple & 123 & 0.7561 & 0.4312 & 42.54 & 9.81 & 0.3415 & 0.4761 \\
\hline Microsoft & 9 & 0.8889 & 0.3333 & 44.67 & 10.97 & 0.4444 & 0.5270 \\
\hline Others & 100 & 0.7500 & 0.4352 & 44.84 & 11.36 & 0.3700 & 0.4852 \\
\hline Total & 1869 & 0.6699 & 0.4704 & 45.15 & 10.96 & 0.3328 & 0.4713 \\
\hline \multicolumn{8}{|l|}{2015} \\
\hline KDDI & 237 & 0.6709 & 0.4709 & 50.67 & 11.30 & 0.4093 & 0.4927 \\
\hline SoftBank & 188 & 0.6383 & 0.4818 & 50.77 & 12.37 & 0.3457 & 0.4769 \\
\hline Google & 589 & 0.7114 & 0.4535 & 46.65 & 12.31 & 0.3497 & 0.4773 \\
\hline Apple & 414 & 0.6643 & 0.4728 & 45.43 & 11.32 & 0.3285 & 0.4702 \\
\hline Others & 55 & 0.7273 & 0.4495 & 50.18 & 12.91 & 0.3455 & 0.4799 \\
\hline Total & 1873 & 0.6829 & 0.4655 & 48.38 & 12.05 & 0.3550 & 0.4787 \\
\hline
\end{tabular}


Table A2 Summary statistics of individual characteristics over handset OS cont. Yearly Household Income (JPY)

\begin{tabular}{ccccccc} 
& $\sim 3 \mathrm{M}$ & $3 \sim 5 \mathrm{M}$ & $5 \sim 7 \mathrm{M}$ & $7 \sim 1 \mathrm{M}$ & $10 \sim 15 \mathrm{M}$ & $15 \mathrm{M} \sim$ \\
\hline \hline 2012 & & & & & & \\
NTT & 121 & 199 & 167 & 141 & 72 & 11 \\
KDDI & 71 & 99 & 91 & 77 & 29 & 13 \\
SoftBank & 57 & 89 & 78 & 69 & 18 & 3 \\
Google & 20 & 60 & 62 & 57 & 24 & 9 \\
Apple & 15 & 25 & 32 & 36 & 12 & 3 \\
Microsoft & 2 & 3 & 1 & 1 & 1 & 1 \\
Others & 18 & 27 & 23 & 19 & 10 & 3 \\
\hline Total & 304 & 502 & 454 & 400 & 166 & 43 \\
\hline \hline 2015 & & & & & & \\
NTT & 87 & 106 & 78 & 80 & 30 & 9 \\
KDDI & 56 & 67 & 52 & 40 & 19 & 3 \\
SoftBank & 46 & 44 & 48 & 34 & 13 & 3 \\
Google & 97 & 148 & 154 & 116 & 60 & 14 \\
Apple & 48 & 106 & 94 & 100 & 51 & 15 \\
Others & 10 & 16 & 12 & 13 & 4 & 0 \\
\hline Total & 344 & 487 & 438 & 383 & 177 & 44 \\
\hline \hline
\end{tabular}


Table A3 Summary statistics of individual characteristics over handset OS cont.

\begin{tabular}{cccccccccc}
\hline Region & Hokkaido & Tohoku & Kanto & Hokuriku & Chubu & Kinki & Chugoku & Shikoku & Kyusyu \\
\hline $\mathbf{2 0 1 2}$ & & & & & & & & & \\
NTT & 28 & 37 & 276 & 31 & 71 & 134 & 32 & 26 & 76 \\
KDDI & 16 & 23 & 136 & 16 & 44 & 87 & 19 & 8 & 31 \\
SoftBank & 19 & 19 & 95 & 13 & 48 & 66 & 20 & 6 & 28 \\
Google & 11 & 12 & 110 & 5 & 23 & 47 & 10 & 3 & 11 \\
Apple & 3 & 8 & 51 & 1 & 16 & 24 & 9 & 2 & 9 \\
Microsoft & 1 & 0 & 5 & 0 & 1 & 1 & 0 & 0 & 1 \\
Others & 1 & 5 & 45 & 3 & 10 & 27 & 1 & 1 & 7 \\
\hline Total & 79 & 104 & 718 & 69 & 213 & 386 & 91 & 46 & 163 \\
\hline 2015 & & & & & & & & & \\
NTT & 18 & 31 & 152 & 19 & 48 & 47 & 18 & 19 & 38 \\
KDDI & 12 & 14 & 77 & 11 & 30 & 54 & 13 & 4 & 22 \\
SoftBank & 13 & 12 & 73 & 7 & 21 & 31 & 9 & 7 & 15 \\
Google & 19 & 41 & 188 & 37 & 67 & 126 & 39 & 18 & 54 \\
Apple & 20 & 21 & 155 & 12 & 45 & 87 & 24 & 14 & 36 \\
Others & 2 & 1 & 22 & 4 & 5 & 13 & 1 & 3 & 4 \\
\hline Total & 84 & 120 & 667 & 90 & 216 & 358 & 104 & 65 & 169 \\
\hline \hline
\end{tabular}


Table A4 The estimation results for the app market and cloud storage service choice model of 2012.

\begin{tabular}{|c|c|c|c|c|c|c|}
\hline & \multicolumn{3}{|l|}{ App Market } & \multicolumn{3}{|l|}{ Cloud } \\
\hline \multicolumn{3}{|c|}{ Log likelihood function } & -1542.5 & & & -1007.0 \\
\hline \multicolumn{3}{|c|}{ McFadden Pseudo R-squared } & 0.5759 & & & 0.72312 \\
\hline & Mean & & S.E & Mean & & S.E \\
\hline NTT & -245.1720 & $* * *$ & 11.41764 & -21.0258 & $* * *$ & 3.40898 \\
\hline KDDI & -245.1720 & $* * *$ & 11.41764 & & & \\
\hline SoftBank & -245.1720 & $* * *$ & 11.41764 & -75.3858 & $* * *$ & 18.95292 \\
\hline Google & -11.19 & $* * *$ & 0.8691 & -5.3941 & $* * *$ & 1.04132 \\
\hline Apple & -11.1896 & $* * *$ & 0.86906 & -4.51938 & $* * *$ & 0.28558 \\
\hline Microsoft & & & & -7.530 & $* * *$ & 2.51571 \\
\hline Others & -245.17 & $* * *$ & 11.4176 & -5.84385 & $* * *$ & 1.0975 \\
\hline$y_{i j}$ & -23.0772 & $* * *$ & 2.5365 & -14.3314 & $* * *$ & 2.81345 \\
\hline \multirow[t]{2}{*}{$\hat{\mu}_{i j}$} & 52.103 & $* * *$ & 1.70078 & 15.9803 & $* * *$ & 2.73447 \\
\hline & Std.Dev & & S.E & Std.Dev & & S.E \\
\hline NTT & 155.5940 & $* * *$ & 7.2574 & 7.6605 & $* * *$ & 1.48231 \\
\hline KDDI & 155.594 & $* * *$ & 7.2574 & & & \\
\hline SoftBank & 155.5940 & $* * *$ & 7.25741 & 38.6895 & $* * *$ & 9.6525 \\
\hline Google & 6.125 & $* * *$ & 0.566 & 1.2745 & & 0.93699 \\
\hline Apple & 6.12514 & $* * *$ & 0.56561 & 0.09467 & & 0.57635 \\
\hline Microsoft & & & & 2.58495 & $*$ & 1.35609 \\
\hline Others & 155.59 & $* * *$ & 7.257 & 2.6802 & $* * *$ & 0.76279 \\
\hline$y_{i j}$ & 92.121 & $* * *$ & 4.0327 & 0.5312 & & 1.1222 \\
\hline$\hat{\mu}_{i j}$ & 34.4124 & $* * *$ & 1.0356 & 15.5817 & $* * *$ & 2.74343 \\
\hline
\end{tabular}

Note: $* * *, * *, *$ mean significances at $1 \%, 5 \%, 10 \%$ level by $\mathrm{Z}$ statistics. 
Table A5 The elasticities of mail, search, and map services of 2012.

\begin{tabular}{lrlrl}
\multicolumn{2}{c}{ App Market } & \multicolumn{2}{l}{ Cloud } \\
\hline \hline NTT & 0.3457 & $* * *$ & -2.0088 & $* * *$ \\
KDDI & 0.177 & $* * *$ & & \\
SoftBank & 0.1351 & $* * *$ & -0.1788 & $* * *$ \\
Google & 0.0010 & & -0.4972 & $* * *$ \\
Apple & 0.0012 & & -0.1667 & $* * *$ \\
Microsoft & & & -0.0044 & $* * *$ \\
Others & -0.0108 & $* * *$ & -0.0729 & $* * *$ \\
\hline \hline
\end{tabular}

Note: $* * *, * *, *$ mean significances at $1 \%, 5 \%, 10 \%$ level by $\mathrm{Z}$ statistics. 
Table A6 The estimation results for the payment, music, cloud storage, and app market service choice model of 2015.

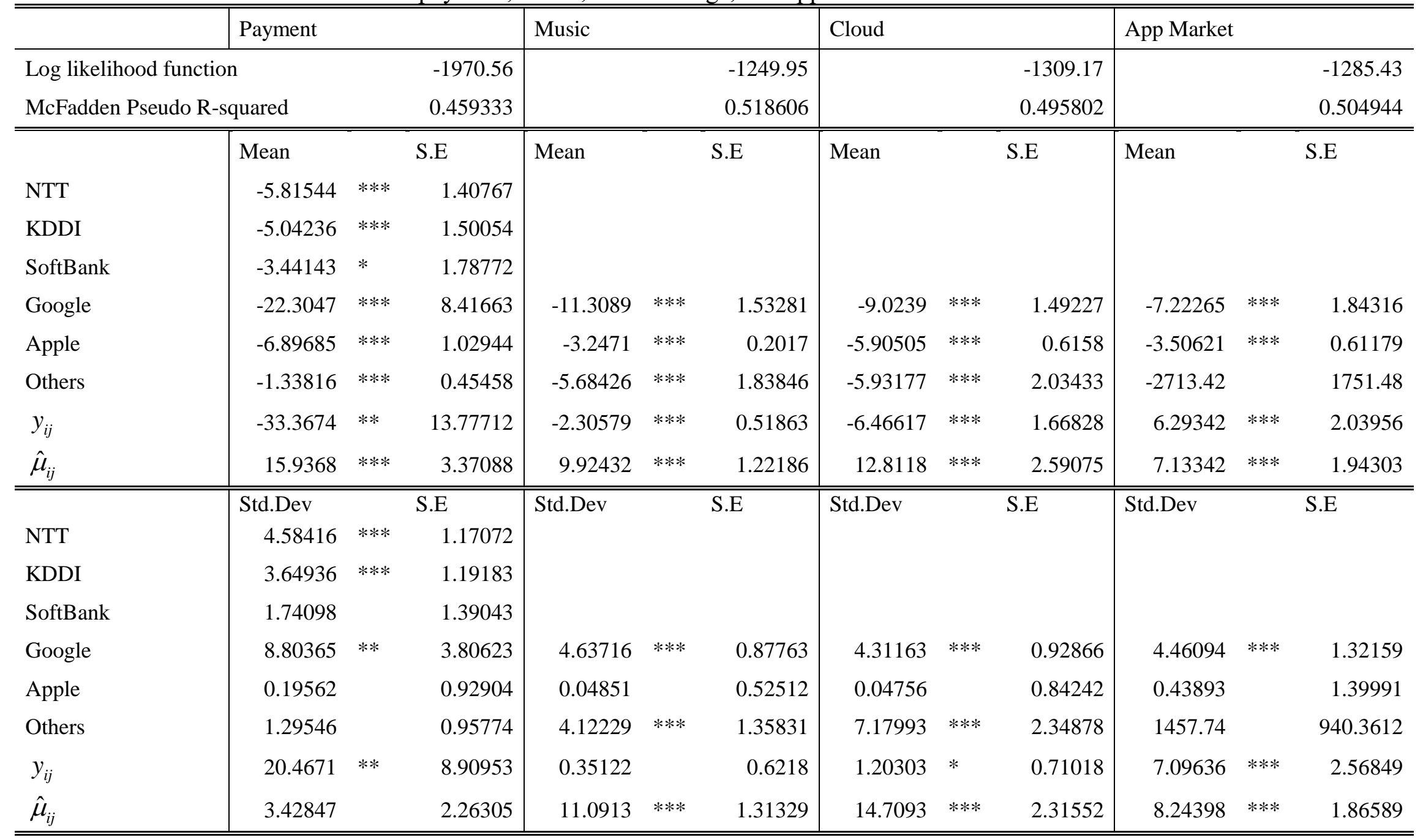

Note: ***,**, mean significances at $1 \%, 5 \%, 10 \%$ level by $\mathrm{Z}$ statistics. 
Table A7 The elasticities of payment, music, cloud storage, and app market services of 2015.

\begin{tabular}{|c|c|c|c|c|c|c|c|c|}
\hline & Payment & & Music & & Cloud & & App Market & \\
\hline NTT & -0.0858 & $* * *$ & & & & & & \\
\hline KDDI & -0.0804 & $* * *$ & & & & & & \\
\hline SoftBank & -0.086 & $* * *$ & & & & & & \\
\hline Google & 0.2867 & $* * *$ & -0.1766 & $* * *$ & -0.4007 & $* * *$ & 0.1069 & $* * *$ \\
\hline Apple & -0.0227 & $* * *$ & -0.0704 & $* * *$ & -0.2307 & $* * *$ & 0.0184 & $* * *$ \\
\hline Others & -0.0289 & $* * *$ & -0.4779 & $* * *$ & -0.7597 & $* * *$ & 0.0035 & $* * *$ \\
\hline
\end{tabular}

Note: ***, **, * mean significances at $1 \%, 5 \%, 10 \%$ level by $\mathrm{Z}$ statistics. 